\title{
Pendidikan Islam Berwawasan Kerahmatan
}

\author{
Wage $^{1}$, Makhful $^{2}$, dan Mintaraga Eman Surya ${ }^{3}$ \\ ${ }^{1}$ Universitas Muhammadiyah Purwokerto, Email: wagefsyah.2010@gmail.com \\ ${ }^{2}$ Universitas Muhammadiyah Purwokerto, Email: makhfulfai@gmail.com \\ ${ }^{3}$ Universitas Muhammadiyah Purwokerto, Email: mintaragaesurya@gmail.com
}

\begin{abstract}
Abstrak
Artikel ini mengkaji pendidikan Islam yang berwawasan kerahmatan, yaitu sebuah konsep pendidikan Islam yang soft dan damai. Pendekatan yang digunakan dalam penelitian ini adalah kualitataif, jenis kepustakaan, dengan analisis model analisis isi (content analisys). Hasil penelitian menunjukkan bahwa unsur-unsur pendidikan Islam berwawasan kerahmatan adalah sebagai berikut pertama, sejarahnya, kedua, filsafatnya, ketiga, tujuannya, keempat, materi dan kelima, pengajarannya. Dalam sejarah awal Islam Rasulullah telah meletakkan landasan pendidikan kerahmatan, di mana beliau berhasil mendidik para sahabatnya sehingga antara Muhajirin dan Anshar terjalin persaudaraan yang erat luar biasa. Pendidikan Islam berangkat dari filosofi bahwa manusia sebagai khalifah Allah yang memiliki tugas menjaga keharmonisan hubungan antar sesama. Sebagai manusia mereka diciptakan bersuku-suku dan berbangsa-bangsa dengan tujuan saling kenal dan bersahabat. Dasar dari pendidikan Islam adalah ajaran untuk bersaudara dan bersahabat. Sedangkan tujuan pendidikan Islam berwawasan kerahmatan adalah terbentuknya peserta didik yang memiliki jiwa rahmah dan damai serta mampu menerapkan pergaulan yang harmonis baik terhadap Allah, sesama manusia, makhluk lain, lingkungan dan dirinya sendiri. Materi pendidikan menonjolkan dan mengutamakan agama dan akhlak dalam berbagai tujuannya, cakupan dan kandungan kurikulum Pendidikan Islam kerahmatan bersifat luas dan menyeluruh. Metode pembelajaran yang dipergunakan adalah holistic-partisipatoris, yaitu metode yang memungkinkan peserta didik untuk bertanya, berbagi dan berkolaborasi. Implikasi penelitian ini adalah perlunya mensosialisasikan konsep pendidikan Islam yang soft dan damai, agar lembaga pendidikan dapat menghasilkan peserta didik muslim yang mampu menerapkan ajaran Islam yang damai.
\end{abstract}

Kata kunci : Pendidikan Islam; Kerahmatan; Damai

\section{Abstract}

This article examines Islamic education with the insight of mercy, which is a soft and peaceful Islamic education concept. The approach used in this research is qualitative, type of literature, 
in analyzing the data using a content analysis model. The results showed that the elements of Islamic education with a mercy insight were as follows: first, history, second, philosophy, third, objectives, fourth, material and fifth, its teaching. In the early history of Islam the Prophet had laid the foundation for education of mercy, where he succeeded in educating his companions so that Muhajirin and Ansar established an extraordinary close friendship. Islamic education departs from the philosophy that humans are the caliph of Allah who has the duty to maintain harmonious relations between people. The basis of Islamic education is the teaching to be brothers and friends. Meanwhile, the purpose of Islamic education with the insight of mercy is the formation of students who have a spirit of mercy and peace and are able to implement harmonious relationships with God, fellow humans, other creatures, the environment and themselves. Educational materials highlight and prioritize religion and morals in various purposes, the scope and content of the Islamic Education curriculum is broad and comprehensive. The learning method used is holistic-participatory, which is a method that allows students to ask questions, share and collaborate.

Keywords: Islamic Education; Mercy; Peace

\section{Pendahuluan}

Masih banyak warga dunia yang memandang Islam sebagai agama teror dan perang dan oleh karenanya mereka berusaha mendiskriditkan Islam dengan berbagai cara. Sudah saatnya kaum muslimin menjawab tuduhan mereka yang tidak berdasar tersebut dengan berbagai cara dan di dalam berbagai kesempatan, agar masyarakat dunia semakin memahami bahwa tuduhan seperti itu tidak benar.

Pendidikan Islam sebagai cerminan institusi Islam yang memiliki posisi amat strategis untuk menjadi corong dan duta penyiaran Islam sudah selayaknya dikemas sebagaimana wadahnya, yaitu agama Islam, menjadi institusi penggodog generasi Islam yang rahmatan lilálamin. Di dalam institusi pendidikan Islam inilah generasi Islam diajarkan kerahmatan-kerahmatan dari ajaran Islam ini sehingga mereka memahami dengan baik ajaran Islam yang sesungguhnya, yang jauh dari kekerasan. Memang tidak dipungkiri masih adanya pemahaman yang keliru dari sebagian kaum muslimin yang memandang Islam sebagai agama yang memiliki satu wajah saja, yaitu kekerasan. Padahal semua agama, sebagaimana juga manusia, selalu memiliki dua wajah, yaitu lemah-lembut dan keras, di mana keduanya harus ada secara bersama-sama dan memiliki fungsi masing-masing. Jadi tidak boleh hanya ada satu, tanpa lainnya. Berdasarkan latar belakang di atas maka penulis tertarik untuk menyusun artikel tentang pendidikan Islam berwawasan kerahmatan. 


\section{Metode Penelitian}

Adapun jenis penelitian ini adalah penelitian kepustakaan (library ressearch) dengan analisis data berupa metode conten analysi. Sumber data utama artikel ini dari buku "Peace Education: Kajian Sejarah, Konsep \& Relevansinya dengan Pendidikan Islam" karya M. Nurul Islam Saleh. Lalu buku "Studi Islam Kontemporer Arus Radikalisasi dan Multikulturalisme di Indonesia” karya Syamsul Arifin terutama bagian I. "Mengurai Sengkarut Agama: Konflik, Kekerasan dan Multikulturalisme", bagian II. "Membendung Arus Radikalisasi di Indonesia" dan bagian III. "Deradikalisasi Idiologi Gerakan Islam Transnasional di Indonesia". Dan buku "Studi Islam Perspektif Insider/Outsider" karya M. Arfan Mu'ammar dan Abdul Wahid Hasan dkk khususnya bagian 9. "Agama Cinta dan Toleransi: Dari Islam untuk Perdamaian Dunia (Studi Fethullah Gulen Movement)" ditulis oleh Mursyid Romli.

\section{Hasil dan Pembahasan}

Istilah rahmatan lil'alamin (kerahmatan) terdapat dalam ayat al-Quran surat al-Anbiya ayat 107 "wa ma arsalnaka illa rahmatan lil'alamin". Ketika menafsirkan ayat di atas M. Qurasih Shihab menyatakan bahwa nabi Muhammad SAW diutus untuk menjadi rahmat bagi seluruh alam. Yang menjadi rahmat adalah kepribadian beliau dan ajaran yang beliau bawa (M. Quraish Shihab, 2002). Sudah menjadi pengetahuan umum kaum muslimin bahwa beliau memiliki kepribadian yang sangat agung (al akhlaq al karimah) seperti misalnya sikap penyabar yang tiada duanya, kasih sayang, pandai menahan marah, tidak pernah iri-dengki dan suka memberi maaf, sehingga dalam pergaulan tidak pernah menyakiti orang lain. Dan saat dizalimi oleh orang lainpun beliau tidak mau membalasnya, sebaliknya malah membalas dengan kebaikan.

Rahmat berupa kehadiran Nabi Muhammad SAW bukan hanya dirasakan oleh umat Islam dan bukan hanya oleh manusia, namun binatangpun ikut merasakannya. Misalnya beliau melarang umatnya mengendarai binatang dengan beban berlebih. Beliau juga melarang mengurung binatang tanpa diberinya makan dan bagi yang melakukannya diancam akan masuk neraka. Di lain waktu beliau menyatakan bahwa seorang yang bergelimang dosa diampuni Tuhan karena dia memberi minum anjing yang kehausan. 
Yusuf Al-Qardhawi menjelaskan bahwa surat al-Anbiya ayat 107 di atas bersama ayat-ayat lain seperti ayat 1 surat al-Furqan, ayat 87-88 surat Shad, ayat 90 surat al-An'am, ayat 158 surat al-A'raf dan ayat 28 surat Saba' menunjukkan bahwa risalah Islam bersifat universal yang berlaku bagi seluruh umat manusia dan rahmat bagi seluruh hamba Allah siapapun dan di manapun ia berada (rahmatan lil 'alamin). Umat Islam tidak boleh memonopoli kebaikan dan cahaya bagi dirinya sendiri (Al-Qardhawi, 1999) yang dibawa Islam antara lain: pertama, membebaskan manusia dari perbudakan terhadap sesama manusia. Nabi Muhammad SAW bersabda. "Janganlah salah seorang di antara kalian mengatakan: Hai budak lakilakiku, hai budak perempuanku, akan tetapi katakanlah: Hai pemudaku (lakilaki), hai pemudiku (perempuan).” (HR Bukhari dan Muslim). Banyak hadits Nabi SAW yang memerintahkan kaum muslimin untuk memerdekakan budak. Hal ini karena berangkat dari ajaran dasar al-Quran yang menyatakan bahwa seluruh manusia itu berkedudukan sama, yang membedakan adalah takwanya, bukan ras atau hal-hal yang beresifat fisik (QS Al-Hujurat ayat 13).

Dalam Al-Quran terdapat sembilan ayat yang berkaitan dengan pembebasan budak. Dengan rincian enam ayat diungkapkan secara lugas dan tersurat, Q.S. Al-Baqarah (2): 177, Q.S. An-Nisa (4): 92, Q.S. Al-Ma冈idah (5): 89, Q.S. AnNur (24): 33, Q.S. Mujadalah (58): 3, Dan Q.S. Al-Balad (90): 13, Dan Tiga Ayat Dinyatakan Secara Tersirat, Yakni: Q.S. Ath-Taubah (9): 60, Q.S. Al-Anfal (8): 67, Dan Q.S. Muhammad (47): 4,91. Semua sumber perbudakan klasik telah dihapuskan oleh Islam kecuali satu sumber saja yakni perbudakan akibat peperangan.

Wahid menyebutkan tiga metode yang digunakan oleh nabi Muhammad S.A.W. dalam upayanya menghapus praktik perbudakan yaitu: pertama, anjuran memerdekakan budak dengan menentukan kafarat-kafarat sebagai tebusan atas suatu kesalahan yang yang dilakukan seseorang. Kedua, menanamkan pemahaman tentang adanya kewajiban antara kedua belah pihak (majikan dan budak), dalam taqwa kepada Allah hal ini diperkuat dengan anjuran untuk mendidik budak dan menikahinya. Ketiga, menerapakan persaudaraan antara budak dan tuannya (Wahid, 2015). Lebih jelasnya, posisi Islam dalam menolak perbudakan dapat dilihat dalam upayanya mengurangi laju perkembangan praktik perbudakan dengan dua cara, yaitu mempersempit pintu masuk terjadinya perbudakan dan membuka selebar-lebarnya pintu keluar dari perbudakan. Cara yang pertama, 
yaitu mempersempit peluang terjadinya praktik perbudakan, direalisasikan dengan melarang seseorang memperbudak orang lain. Rasulullah saw bersabda:

"Tiga kelompokyang tidak diterima shalat mereka: seseorangyang mengimami suatu kaum padahal mereka membencinya, seseorang yang mengerjakan shalat setelah keluar dari waktunya dan seseorang yang memperbudak orang yang merdeka" (H.R Ibn Mâjah13),

Adapun cara kedua yang ditempuh oleh Islam untuk mengikis praktik perbudakan adalah dengan membuka lebar pintu kemerdekaan bagi seorang budak. Hal tersebut ditempuh setidaknya dengan tiga cara, yaitu:

1. Memfasilitasi pemerdekaan budak lewat dana zakat, seperti yang disebutkan dalam Q.S. At-Taubah ayat 60 yang artinya:

"Sesungguhnya zakat-zakat itu hanyalah untuk orang-orang fakir, orangorang miskin, pengurus-pengurus zakat, para muallaf yang dibujuk hatinya, (memerdekakan) budak, orang-orang yang berhutang, untuk jalan Allah dan orang-orang yang sedang ada dalam perjalanan, sebagai suatu ketetapan yang diwajibkan Allah; dan Allah Maha Mengetahui lagi Maha Bijaksana" (Q.s. AtTaubah: 60).

2. Melalui pembayaran kafarat (denda) Pembebasan budak lewat jalur pembayaran kafârah banyak terdapat di al Qur'an, di antaranya seperti kafarat bagi pembunuhan Qs. Al-Nisâ: 92,28 kafarat melanggar sumpah al-Mâidah: 89,29 kafarat ? ?ihâr al-Mujadillah: 3 .

3. Melalui anjuran dengan ganti keselamatan dari api neraka Selain lewat jalur pembayaran kafarah, Islam juga menjadikan pembebasan budak sebagai amal shalih yang dijanjikan dengan dengan ganti yang besar, yaitu berupa pengampunan dosa sebagaimana Rasulullah saw bersabda:

"Barangsiapa yang memerdekakan budak yang berimana maka akan menjadi tebusan (pelindung) baginya dari api neraka”" (H.R. Abû Dawûd) (Fatkhi dan Lisalam, 2018).

Kedua, ajaran persaudaraan dan persamaan manusia. Islam menekankan pentingnya persaudaraan. Dalam ayat 10 surat al-Hujurat Allah menegaskan bahwa orang mu'min harus bersaudara. Menurut hadits riwayat imam Bukhary dan Muslim sifat orang mu'min itu bersaudara. Mereka bagaikan satu tubuh, di mana jika satu anggota tubuh sakit maka bagian dari anggota tubuh lainnya 
akan ikut merasa sakit (Aminah, 2015). Persaudaraan (ukhuwwah) dalam Islam dimaksudkan bukan sebatas hubungan kekerabatan karena faktor keturunan, tetapi yang dimaksud dengan persaudaraan dalam Islam adalah persaudaraan yang diikat oleh akidah (sesama muslim) dan persaudaraan karena fungsi kemanusiaan (sesama manusia makhluk Allah SWT). Kedua persaudaraan tersebut sangat jelas dicontohkan oleh Rasulullah SAW, yaitu mempersaudarakan antara kaum Muhajirin dan kaum Anshar, serta menjalin hubungan persaudaraan dengan suku-suku lain yang tidak seiman dan melakukan kerja sama dengan mereka. Allah SWT berfirman tentang persaudaraan, yang artinya:

"Sesungguhnya orang-orang mukmin itu bersaudara, karena itu damaikanlah antara kedua saudaramu (yang berselisih) dan bertakwalah kepada Allah agar kamu mendapat rahmat." (QS. Al-Hujurat:10).

Pada ayat di atas Allah SWT menegaskan dua hal pokok, yaitu: Pertama, bahwa sesungguhnya orang-orang mukmin itu bersaudara. Kedua, jika terdapat perselisihan antar saudara, kita diperintahkan oleh Allah SWT untuk melakukan islah (upaya perbaikan atau perdamaian). Apa indikasi dari suatu persaudaraan? Rasulullah SAW bersabda:

"Demi Allah yang menguasai diriku! Seseorang di antara kalian tidak dianggap beriman kecuali jika dia menyayangi saudaranya sesama mukmin sama seperti dia menyayangi dirinya sendiri." (HR. Muslim).

Selain itu Rasulullah SAW juga menegaskan bahwa, seorang muslim adalah orang yang lidah dan tangannya tidak menyakiti muslim lain, dan orang yang berhijrah adalah orang yang meninggalkan semua larangan Allah (HR.Bukhari). Rasulullah SAW mengikatkan hati-hati sahabatnya antara kaum muhajirin dengan kaum anshar terpatrikan dalam diri dan jiwa mereka sehingga terbentuk ikatan persaudaran seiman yang kokoh. Refleksi persaudaan sahabat nabi menjadi uswah (contoh) referensi bagi umat yang terukir dalam sejarah manusia dan tersebut dan ayat Alqur'an. Sebuh potret persaudaraan yang dibangun menjadi intraksi sosial yang maju, dinamis, dan menjadi referensi untuk sebuah masyarakat madani (Siregar, 2018).

Menurut Islam seluruh manusia diciptakan dengan membawa kedudukan yang sama. Diciptakannya manusia dengan berbagai perbedaan baik jenis kelamin, warna kulit, suku dan ras tidak ada tujuan lain selain agar satu sama lain saling kenal- 
mengenal dan bersaudara (Al-Quran ayat 13 surat al-Hujurat). Menurut Sayyid Qutub Islam telah mengajarkan persamaan antar sesama manusia. Ayat 92 dari surat an-Nisa secara jelas memberikan hak yang sama antara orang Islam dengan non Islam sepanjang telah terdapat kesepakatan damai. Mengenai perbedaan jenis kelamin antara laki-laki dan perempuan, Sayyid Qutb berkomentar bahwa Islam telah memberikan jaminan yang sama dan sempurna kepada kaum wanita sejajar dengan kaum pria, kecuali dalam beberpa segi yang berkaitan dengan karakter biologis dan tabiat masingmasing jenis kelamin yang tidak sampai berpengaruh pada kedudukan hakiki jenis kelamin manusia (Awad, 2019).

Ketiga, ajaran tentang keadilan bagi seluruh manusia. Islam mengajarkan bahwa berlaku adil itu wajib dilakukan oleh semua orang beriman. Kaum mukmin tidak boleh bersikap subjektif dalam menerapkan suatu keputusan dan memperlakukan orang. Nabi Muhammad sendiri telah mencontohkan untuk berlaku adil walaupun terhadap orang yang terdekat. Dia bersabda "Seandainya Fatimah (putrinya) mencuri tentu akan aku potong tangannya" (Al-Hadits).

Islam memerintahkan kepada setiap manusia untuk berbuat adil atau menegakkan keadilan pada setiap tindakan perbuatan yang dilakukan. Dalam QS An-Nisaa ayat 58 yang artinya sesungguhnya Allah menyuruhmu menyampaikan amanat kepada yang berhak menerimanya dan menyuruh kamu apa bila menetapkan hokum di antara manusia supaya kamu menetapkan dengan adil. Sesungguhnya Allah memberikan pengajaran yang sebaik baiknya kepadamu. Sesungguhnya Allah Maha mendengar dan Maha melihat. Keadilan merupakan hal penting dalam kehidupan berbangsa dan bernegara (Rangkuti, 2017).

Keempat, ajaran tentang perdamaian dunia. Di antara ayat yang memerintahkan untuk menghentikan permusuhan dan beralih ke perdamaian adalah surat Al-Anfal ayat 61 dan surat An-nisa ayat 4. Menurut Imam Ibnu Katsir, ayat ke-4 Q.S. An-Nisaa ini sungguh menarik. Perdamaian dalam ayat ini, walau diletakkan di akhir, ternyata menjadi menarik, karena digandengkan dengan perintah-perintah lain yang sangat baik, yaitu sedekah, dan berbuat makruf. Hal ini menunjukkan bahwa perdamaian memiliki nilai yang setara dengan sedekah dan berbuat makruf (Tafsir Ibnu Katsir, Bab 114, Juz 2, hlm. 412).

Islam sendiri dari sisi kebahasaan memiliki makna damai. Oleh sebab itu tidak berlebihan jika Islam merupakan agama perdamaian. Setidaknya ada tiga alasan, 
yakni: pertama, Islam itu sendiri berarti kepatuhan diri (submission) kepada Tuhan dan perdamaian (peace). Kedua, salah satu dari nama Tuhan dalam al-asma alhusna adalah Yang Maha Damai (al-salam). Ketiga, perdamaian dan kasih sayang merupakan keteladanan yang dipraktikkan oleh Nabi Muhammad SAW. Lebih lanjut, Zuhairi Misrawi menambahkan bahwa perdamaian merupakan jantung dan denyut nadi dari agama. Menolak perdamaian merupakan sikap yang bisa dikategorikan sebagai menolak esensi agama dan kemanusiaan (Nurcholis, 2018).

Kelima, persaudaraan dengan non muslim. Ajaran ini misalnya terlihat dalam QS Al-Mu'minun ayat 52 yang mengakui Ahli Kitab sebagai satu umat dengan kaum muslimin, QS Al-Maidah ayat 5 yang menyatakan bahwa makanan Ahli Kitab halal bagi kaum muslimin, QS Al-Hajj ayat 40 yang menyatakan bahwa perang dalam Islam adalah untuk melindungi tempat-tempat ibadah apapun agamanya.

Islam mengajarkan umatnya untuk menghormati umat agama lain, melarang mereka menghina agama lain, mencela sesembahannya, atau memaksa non-Muslim untuk memeluk Islam, bahkan Islam mengajarkan umatnya untuk mengakui non-Muslim sebagai saudara. (Armayanto, 2013). Alasan yang dikemukakan alQur'an tentang persaudaraan dengan non muslim adalah bahwa manusia itu satu sama lain bersaudara karena mereka berasal dari sumber yang satu. QS. 49 alHujurât: 13 menegaskan hal ini:

"Hai manusia, sesungguhnya Kami menciptakan kamu dari seorang lakilaki dan seorang perempuan dan menjadikan kamu berbangsa-bangsa dan bersuku-suku supaya kamu saling kenalmengenal. Sesungguhnya orang yang paling mulia di antara kamu di sisi Allah ialah orang yang paling bertakwa. Sesungguhnya Allah Maha Mengetahui lagi Maha Mengenal.” (QS. 49 alHujurât: 13).

"Hai sekalian manusia, bertakwalah kepada Tuhanmu yang telah menciptakan kamu dari seorang diri (Adam), dan dari padanya Allah menciptakan isterinya (Hawa), dan dari pada keduanya Allah memperkembangbiakkan laki-laki dan perempuan yang banyak. Dan bertakwalah kepada Allah yang dengan (mempergunakan) nama-Nya kamu saling meminta satu sama lain, dan (peliharalah) hubungan silaturrahim. Sesungguhnya Allah selalu menjaga dan mengawasi kamu.” (QS. 4 al-Nisầ: 1).

Misi utama ajaran Islam adalah membebaskan manusia dari berbagai bentuk anarki dan ketidakadilan. Karena Allah Maha Adil, maka tidak mungkin di dalam 
kitab suci-Nya mengandung konsep-konsep yang tidak mencerminkan keadilan. Jika ada nilai atau norma yang tidak sejalan dengan prinsip-prinsip keadilan dan hak-hak asasi secara universal, maka nilai dan norma tersebut perlu direaktualisasi penafsirannya. Dalam perspektif Islam, kemanusiaan hakiki adalah kembali kepada fitrah manusia itu sendiri; sebagai manusia yang cenderung kepada nilainilai keagamaan yang substansial, dan nilai-nilai moral-spiritual yang bersifat perennial. Manusia adalah theomorfic being yang bertugas sebagai khalifah di muka bumi. Oleh karena itu, manusia dituntut untuk bercermin pada sifat-sifat Allah Yang Maha Pengasih, Maha Pengatur, dan Maha Adil untuk diaktualisasikan dalam realitas kehidupan nyata, sehingga wajah dunia ini menjadi dunia yang penuh kasih sayang, keteraturan, keadilan, kedamaian dan kesejahteraan.

Al-Quran menegaskan bahwa kedatangan nabi Muhammad dengan misi risalah Islam adalah sebagai rahmat bagi semesta alam. Rahmat berarti pembebasan manusia dari segala macam yang tidak sesuai dengan karakter dan tabiat manusia dan alam itu sendiri. Pada tataran nilai, Islam sejak awal mengajarkan kebaikan dan moralitas luhur, dan pada saat yang sama melarang segala perilaku jahat. Dalam Islam disebutkan, bahwa kehadirannya adalah sebagai rahmat bagi semesta alam. Cita-cita moral ideal Islam adalah membangun dunia, di mana orang Islam maupun non-Islam hidup bersama menikmati keadilan, kedamaian, kasih sayang dan keharmonisan. Inilah tantangan dan persoalan dalam kehidupan modern sekarang ini. Adalah tugas semua elemen masyarakat, terutama para pemimpin agama dan para intelektual untuk menangkap pesan-pean moral agama yang dapat membawa kepada kehidupan yang harmonis di tengah pluralitas (Zuhdi, 2011).Uraian di atas membawa kita pada keyakinan bahwa Islam adalah agama rahmat. Itulah citra Islam di dalam konsep. Namun di dalam sejarah citra Islam yang demikian belum sepenuhnya, menjadi kenyataan, bahkan mungkin antara idealita dan realita masih fivety-fivety. Memang faktor penyebabnya banyak, salah satu di antaranya adalah adanya upaya secara sengaja dari pihak musuh Islam untuk menjadikan Islam sebagai agama paradoks dengan citra kerahmatan. Namun bagaimanapun juga, upaya dari dalam, dengan pengertian yang dilakukan sendiri oleh umat Islam, untuk mewujudkan Islam sebagai agama rahmat tetap perlu dilakukan, salah satunya adalah melalui pendidikan.

Pentingnya kajian tentang pendidikan kerahmatan (rahmatan lil'alamin) disebabkan oleh adanya ancaman dari luar dan dari dalam; ancaman dari luar 
berupa stigma negatif terhadap Islam yang dilakukan oleh non muslim. Ancaman dari dalam berupa kesalahan paham dari umat muslim sendiri terhadap ajaran agamanya, di mana mereka memandang bahwa Islam adalah agama kekerasan, yang oleh karenanya mereka akan senantiasa mengobarkan perang terhadap non muslim. Kondisi seperti itu tentu tidak menguntungkan bagi Islam itu sendiri, karena dengan demikian maka orang non muslim, terutama yang selama ini sudah mencap Islam sebagai agama radikal, akan menemukan pembenaran. Jika demikian maka semakin tenggelamlah Islam ke dalam stigma negative, yaitu sebagai agama perang, agama teror dan agama radikal, yang oleh karenanya masyarakat dunia akan semakin kompak untuk memerangi dan mengenyahkan Islam dari muka bumi. Demi menghindari terjadinya hal tersebut maka perlu dilakukan usaha konkrit, salah satunya adalah dengan mengembangkan pendidikan Islam berwawasan kerahmatan (rahmatan lil 'alamin). Mengapa melalui pendidikan Islam? Sebagaimana diketahui bersama, pendidikan merupakan sarana ampuh untuk melakukan sosialisasi dan internalisasi nilai. Rasulullah SAW berhasil mengubah masyarakat Arab Jahiliyah menjadi masyarakat Islami yang berbalik $180^{\circ}$ hanya dalam waktu 23 tahun (Mujamil Qomar,2014: 201). Apa yang dilakukan oleh Rasulullah SAW itu tidak lain adalah melalui pendidikan. (Safrudin Aziz, 2015: 18). Bahkan pendidikan ini bisa diandalkan untuk mengatasi kelemahan umat Islam. Pendidikan merupakan senjata paling strategis dalam memajukan umat Islam dan peradabannya. Negara maju manapun selalu diawali oleh pendidikan yang mapan.

Mengacu pada konsep Peace Education sebagaimana ditulis oleh M. Nurul Ikhsan Saleh (Saleh, 2012) bahwa unsur-unsur pendidikan Islam berwawasan rahmatan lil'alamin adalah sebagai berikut pertama, sejarahnya, kedua, filsafatnya, ketiga, tujuannya, keempat, materi dan kelima, pengajarannya. Sejarah Islam menjelaskan bahwa Nabi Muhammad SAW sebagai pembawa risalah Islam memberikan pengajaran kepada para sahabatnya berupa; ke dalam mempererat tali persaudaraan sesama muslim sehingga terciptalah persaudaraan antara kaum muhajirin dan anshar, keluar, Nabi SAW mengajarkan sahabatnya untuk menghormati pemeluk agama lain, baik Yahudi maupun penganut agama nenek moyang. Selanjutnya agar tercipta hubungan harmonis di antara mereka beliau menginisiasi dirumuskannya Piagam Madinah, di mana isinya menjamin kebebasan beragama dan hak-hak politik tertentu, dan kewajiban mengupayakan 
keamanan bersama bagi seluruh penduduk (Saleh, ibid: 117-118).

Dalam filsafat pendidikan Islam disebutkan bahwa tujuan diciptakannya manusia bersuku-suku dan berbangsa-bangsa adalah agar satu sama lain saling kenal-mengenal (QS Al-Hujurat ayat 13), dengan makna lain agar tercipta hubungan yang harmonis. Selain itu manusia memiliki fungsi dan kedudukan sebagai hamba dan khalifah Allah. Sebagai hamba manusia bertugas untuk menyembah Allah. Tujuan dari penyembahan kepada Allah adalah agar manusia memiliki spiritualitas yang tinggi. Keadaan ini akan memungkinkan manusia memiliki jiwa rendah hati, tidak sombong, dan sikap positif lainnya sehingga memungkinkannya untuk dapat berhubungan dengan orang lain secara baik. Sebagai khalifah, manusia memiliki tugas untuk memakmurkan bumi (QS Hud ayat 6) yang berarti mengelola bumi untuk memenuhi kepentingan mereka dan menjaga kelestariannya. Bila hal ini dihubungkan dengan ayat lain yang berbicara tentang awal penciptaan manusia (QS Al-Baqarah ayat 30) terlihat bahwa sebagai khalifah, maka manusia memiliki tugas untuk menjaga perdamaian (Saleh, ibid: 120-122, bandingkan dengan Toto Suharto 2014: 64-72).

Berangkat dari tujuan Islam yaitu untuk mendidik umatnya menjadi orang yang mampu menciptakan hubungan harmonis baik dengan tuhannya yaitu Allah SWT maupun dengan sesama manusia, makhluk lain dan lingkungannya, serta harmonis dengan dirinya sendiri seperti dijelaskan di atas, maka tujuan pendidikan Islam berwawasan rahmatan lil 'alamin adalah terbentuknya peserta didik yang memiliki jiwa rahmah dan damai serta mampu menerapkan pergaulan yang harmonis baik terhadap Allah, sesama manusia, makhluk lain, lingkungan dan dirinya sendiri. Al Abrasyi menyatakan bahwa kurikulum Pendidikan Islam sangat memperhatikan enam hal, dua di antaranya adalah:

1. Pelajaran agama diberikan dengan maksud terbentuknya jiwa peserta didik yang sempurna dan utama

2. Pelajaran agama mendapat prioritas, karena pelajaran ini merupakan sendi bagi pembentukan moral yang luhur (Toto Suharto, ibid: 100-101).

Metode pembelajaran yang dipergunakan adalah holistic-partisipatoris, yaitu metode yang memungkinkan peserta didik untuk bertanya, berbagi dan berkolaborasi. Peserta didik terlibat dialog dengan guru atau sesama mereka.Guru lebih banyak bertindak sebagai fasilitator daripada figure otoritas. Pembelajaran 
holistic-partisipatoris berarti memberikan kesempatan bagi peserta didik untuk bekerjasama dalam belajar, bukan bersaing satu sama lain. Dari sini diharapkan akan meningkatkan motivasi belajar, meningkatkan hubungan antar peserta didik, menghilangkan sikap individualism, perpecahan dan prasangka buruk (M. Nur Ikhsan Saleh, ibid: 135-137).

\section{Simpulan}

Agamakerahmatan (rahmatan lil'alamin), maksudnya agama yang hadir untuk membawa kebaikan bagi seluruh alam. Contoh kongkritnya adalah kehadiran Nabi Muhammad SAW di tengah masyarakat Arab ketika itu; keberadaannya dirasakan sebagai rahmat oleh semua makhluk, baik oleh sesama manusia muslim atau non muslim, oleh hewan, tumbuhan bahkan benda mati sekalipun. Saat ini Islam dipersepsikan oleh orang non Islam sebagai agama kekerasan atau terror. Bahkan sebagian umat Islam juga masih ada yang memandang non muslim sebagai musuh secara fisik, dan oleh karenanya memperlakukan mereka layaknya musuh. Kelompok inilah yang suka main teror terhadap non muslim seperti mereka yang terlibat kasus pengeboman di beberapa tempat.

Kondisi seperti itu tidak bisa dibiarkan, melainkan harus dicegah. Salah satu caranya adalah melalui pendidikan Islam berwawasan kerahmatan (rahmatan lil 'alamin). Hasil penelitian menunjukkan bahwa pendidikan Islam berwawasan kerahmatan memiliki beberapa unsur. Unsur-unsur pendidikan Islam berwawasan kerahmatan (rahmatan lil'alamin) adalah sebagai berikut pertama, sejarahnya, kedua, filsafatnya, ketiga, tujuannya, keempat, materi dan kelima, pengajarannya. Dalam sejarah awal Islam Rasulullah telah meletakkan landasan pendidikan kerahmatan (rahmatan lil'alamin), di mana beliau berhasil mendidik para sahabatnya sehingga antara Muhajirin dan Anshar terjalin persaudaraan yang erat luar biasa. Pendidikan Islam berangkat dari filosofi bahwa manusia sebagai khalifah Allah yang memiliki tugas menjaga keharmonisan hubungan antar sesama. Sebagai manusia mereka diciptakan bersuku-suku dan berbangsabangsa dengan tujuan saling kenal dan bersahabat. Dasar dari pendidikan Islam adalah ajaran untuk bersaudara dan bersahabat. Sedangkan tujuan pendidikan Islam berwawasan kerahmatan (rahmatan lil 'alamin) adalah terbentuknya peserta didik yang memiliki jiwa rahmah (kasih-sayang) dan damai serta mampu menerapkan pergaulan yang harmonis baik terhadap Allah, sesama manusia, 
makhluk lain, lingkungan dan dirinya sendiri. Materi pendidikan menonjolkan dan mengutamakan agama dan akhlak dalam berbagai tujuannya, cakupan dan kandungan kurikulum Pendidikan Islam rahmatan lil'alamin bersifat luas dan menyeluruh. Metode pembelajaran yang dipergunakan adalah holisticpartisipatoris, yaitu metode yang memungkinkan peserta didik untuk bertanya, berbagi dan berkolaborasi.

\section{Daftar Rujukan}

Abdullah, Amin. (1999). Studi Agama: Normativitas atau Historisitas? Yogyakarta. Pustaka Pelajar.

Al-Qardhawi, Yusuf. (1999). Berinteraksi dengan Al-Quran. Terj. Abdul Hayyi AlKattani. Jakarta. Gema INsani Press.

Aminah, Siti. (2015). Merajut Ukhuwah Islamiyah dalam Keanekaragaman Budaya dan Toleransi Antar Agama. Jurnal Cendekia Vol 13 No 1.

Anshari, Endang Saifuddin. (1986). Wawasan Islam: Pokok-pokok Pikiran tentang Islam dan Umatnya. Jakarta. Rajawali.

Armayanto, Harda. (2013). Etika Al-Qur'an Terhadap Non-Muslim. Jurnal Tsaqafah. Institut Studi Islam Darussalam Gontor. Vol. 9, No. 2.

Awad. (2019). Islam dan Prinsip Persamaan (Equality). TARBAWI. VOL VIII, NO.2.

Aziz, Safrudin. (2015). Pemikiran Pendidikan Islam: Kajian Tokoh Klasik dan Kontemprer. Yogyakarta. Kali Media.

Bin Syamsuri, Imanudin, dan M. Zaenal Arifin. (2015). Jangan Nodai Agama: Wawasan Al-Quran tentang Pelecehan Agama. Yogyakarta. Pustaka Pelajar.

Departemen Agama RI. (2007). Yayasan Penyelenggara Penerjemah/Penafsir AlQuran, Al-Quran Terjemah Perkata. Bandung. Syaamil Al-Quran.

Fatkhi, Rifqi Muhammad dan Reva Hudan Lisalam. (2018). Membumikan HAM Mengikis Perbudakan (Kajian Maw?û̉ î Terhadap ?adîts-? ?adîts Perbudakan), REFLEKSI. Volume 17, Nomor 2.

Muhaimin. (2013). Rekonstruksi Pendidikan Islam: dari Paradigma Pengembangan, 
Manajemen Kelembagaan, Kurikulum hingga Strategi Pembelajaran. Jakarta. Rajawali Pers.

Nurcholis, Ahmad. (2018). Islam Dan Pendidikan Perdamaian. Al Ibrah. Jurnal Keilmuan dan Pendidikan Islam. Sekolah Tinggi Ilmu Tarbiyah Al-Ibrahimy. Bangkalan. Vol. 3 No.2.

Qomar, Mujamil. (2017). Menggagas Pendidikan Islam. Bandung. Remaja Rosdakarya.

Rangkuti, Afifa. (2017). Konsep Keadilan Dalam Perspektif Islam. Jurnal Pendidikan Islam Tazkiya. Program Studi Pendidikan Agama Islam UIN Sumatera Utara, Vol.VI No.1.

Saleh, M. Nurul Ikhsan. (2012). Peace Education: Kajian Sejarah, Konsep, \& Relevansinya dengan Pendidikan Islam. Jogjakarta. Arruz Media.

Shihab, M. Quraish. (2002). Tafsir Al Misbah,Pesan, Kesan dan Keserasian AlQuran, Vol. 8. Jakarta. Lentera Hati.

------. (1997) Lentera Hati: Kisah dan Hikmah Kehidupan. Bandung. Mizan.

Siregar, Khairul Ikhsan. (2018). Konsep Persaudaraan Sebagai Profetik Sunnah dalam Perspektif Mahasiswa. Jurnal Studi Al-Quran Membangun Tradisi Berfikir Qur'ani, Vol. 14, No. 2.

Soleh, Achmad Khudori dan Erik Sabti Rahmawati. (2011). Kerjasama Umat Beragama dalam Al-Quran Perspektif Hermeneutika Farid Esack. Malang. UIN MALIKI Press.

Subahar, Abdul Halim. (2013). Kebijakan Pendidikan Islam dari Ordonansi Guru Sampai UU Sisdiknas. Jakarta. Rajawali Pers.

Suharto, Toto. (2014). Filsafat Pendidikan Islam: Menguatkan Epistemologi Islam dalam Pendidikan. Jogjakarta. Ar-Ruzz Media.

Wahid, Abdul Hakim. (2015). "Perbudakan Dalam Pandangan Islam, Hadits Dan Siran Nabawiyah: Textual and Contextual Studies", Nuansa, Vol. VIII, No. 2.

Zuhdi, HM. (2011). Visi Islam Rahmatan Lil'alamin: Dialektika Islam dan Peradaban. Akademika. STAIN Jurai Siwo Metro. 